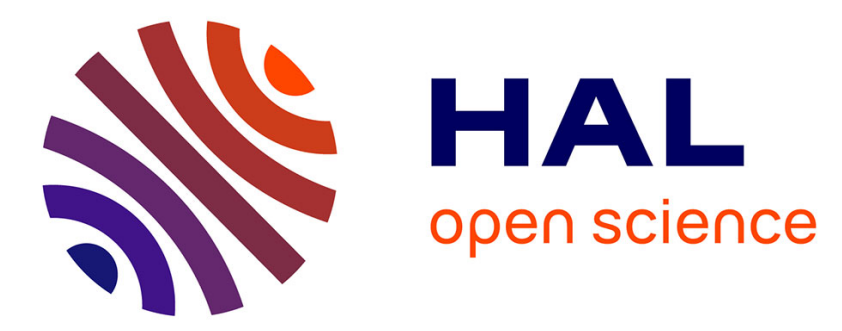

\title{
Backstepping controller with force estimator applied for mobile robot
}

Benaoumeur Ibari, Laredj Benchikh, Kamel Bouzgou, Reda Hanifi Elhachemi, Zoubir Ahmed-Foitih

\section{- To cite this version:}

Benaoumeur Ibari, Laredj Benchikh, Kamel Bouzgou, Reda Hanifi Elhachemi, Zoubir Ahmed-Foitih. Backstepping controller with force estimator applied for mobile robot. Przeglad Elektrotechniczny , 2019, 2019 (10), pp.18-21. 10.15199/48.2019.10.03 . hal-02384553

\section{HAL Id: hal-02384553 \\ https://hal.science/hal-02384553}

Submitted on 28 Nov 2019

HAL is a multi-disciplinary open access archive for the deposit and dissemination of scientific research documents, whether they are published or not. The documents may come from teaching and research institutions in France or abroad, or from public or private research centers.
L'archive ouverte pluridisciplinaire HAL, est destinée au dépôt et à la diffusion de documents scientifiques de niveau recherche, publiés ou non, émanant des établissements d'enseignement et de recherche français ou étrangers, des laboratoires publics ou privés. 


\title{
Backstepping controller with force estimator applied for mobile
} robot

\begin{abstract}
In this paper, we present the concept of nonlinear control technique for trajectory tracking problem of mobile robot type unicycle. the design of the proposed controller is combines a backstepping controller and the force estimator method. The main aim of this study is to design a robust control law in the presence of disturbances using the backstepping with estimation of the forces. The approach consists to estimate the perturbation using an adaptive controller, the effectiveness of the proposed approach is demonstrated through simulation and experimental results.

Streszczenie. W niniejszym artykule przedstawiamy koncepcję techniki sterowania nieliniowego dla problemu ś ledzeniatrajektorii w monocyklu typu robota mobilnego. Konstrukcja proponowanego sterownika łączy w sobie kontroler backstepping i metode estymatora siły. Głównym celem tego badania jest zaprojektowanie solidnego prawa sterowania w obecnoś cżakłóceń z ykorzystując backstepping z oszacowaniem sił. Podejś ciøolega na oszacowaniu perturbacji za pomoca adaptacyjnego kontrolera, skutecznoś ́proponowanego podejś cizostała zademonstrowana za pomoca symulacji i wyników eksperymentalnych. (Backstepping kontroler z estymatorem siły zastosowany dla robota mobilnego)
\end{abstract}

Keywords: Backstepping control, Mobile robot, estimator force

Słowa kluczowe: Kontrola Backstepping, robot mobilny, siła estymatora

\section{Introduction}

These days, a number of robot used for a simple repeat work such as an assembly, coating or welding as well for hazardous industrial fields have been coming to our homes. The last years have been increasingly rapid advances in the field of trajectory tracking of mobile robot, recent developments in this fields have heightened the need of the design a robust control. In order to design controllers for robots, researchers inevitably need models of how the robot actually behave, Many models have been developed for the mobile robot, one of the most common models out is the model of a differential drive mobile robot, it is used in various applications as nuclear power environments with high levels of radiation [1], surveillance [2]

In [3],[4] the proposed control laws is based on the kinematics of the mobile robot. However, in the real experimental, it is important to study the robot dynamics as in [5],[6]. Some motion controllers have been proposed in the field of trajectory tracking, in [7], a control law with an adaptive controller based on the robot dynamics is proposed to estimate the parameters, which are directly related to physical parameters of the robot dynamics, real experimental were reported on a Pioneer 3-DX mobile robot. The control problem of WMR (Wheeled Mobile Robot) with uncertain/unknown mass center is studied in [8], ignoring either input saturation, slipping/skidding uncertainties, actuator failures, or output constraints, the method is validated numerically by simulation and experimental results.

In [9] a robust output tracking controller of unicycle type mobile robot is proposed using a backstepping technique, the stability of the system is analyzed using the Lyapunov theory. Nonlinear PI controller is added in [10], to eliminate the tracking errors and the disturbances, the proposed approach is not tested in the case of the disturbances.

This paper first gives the model of the Wheeled Mobile Robot (kinematics and dynamics) and proposes technique of a control for dynamic model (Backstepping), this model was developed and described by De La Cruz Celso in [11], using the Newton-Euler formalism. The main aim of this study is the synthesis of stabilizing control laws in the presence of disturbances using the combination backstepping controller and the force estimator. The difficulty of control is mainly due to its complex dynamics, nonlinear multi variable and especially in its operation, therefore, the control strategy is based on the decomposition of the original system into two subsystems: the first concerns the position control and the second is the control of the linear and angular velocities.

The remaining part of the paper proceeds as follows: In Section 2 the kinematics and dynamics representation of the Wheeled Mobile Robot is presented. In Section 3 the design of the robust controller for tracking control is developed. Then, in the section 4, the findings of the research is analyzed and discussed, focusing on the effectiveness of used approach. Finally, Section 5 concludes this paper.

\section{Model of Wheeled Mobile Robot}

In this paper, the model of wheeled mobile robot developed by Celso De La Cruz in [11] is used, one advantage of this model is that its input signals are the linear and angular velocities, with are used in the commercial mobile robot, the model is represented in the figure 1 where $u$ and $\omega$ are, respectively, the linear and angular velocities, $\psi$ is the robot orientation, $G$ is the point of required to track a trajectory, $c$ and $d$ are distances.

The kinematics and dynamics model can be written in form:

$$
\begin{aligned}
\left(\begin{array}{c}
\dot{x} \\
\dot{y} \\
\dot{\psi} \\
\dot{u} \\
\dot{\omega}
\end{array}\right) & =\left(\begin{array}{c}
u \cos (\psi)-a w \sin (\psi) \\
u \sin (\psi)+a w \cos (\psi) \\
\omega \\
\frac{\alpha_{3}}{\alpha_{1}} \omega^{2}-\frac{\alpha_{4}}{\alpha_{1}} u \\
-\frac{\alpha_{5}}{\alpha_{2}} u \omega-\frac{\alpha_{6}}{\alpha_{2}} \omega
\end{array}\right) \\
& +\left(\begin{array}{cc}
0 & 0 \\
0 & 0 \\
0 & 0 \\
\frac{1}{2} \alpha_{1} & 0 \\
0 & \frac{1}{2} \alpha_{2}
\end{array}\right)\left(\begin{array}{c}
u_{\text {ref }} \\
\omega_{\text {ref }}
\end{array}\right)
\end{aligned}
$$

Where the parameters $\alpha_{1}, \alpha_{2}, \alpha_{3}, \alpha_{4}, \alpha_{5}$ and $\alpha_{6}$ of the dynamic model are defined in [11]

\section{Design of Backstepping-Force Estimator Controller}

The control structure is constituted of: The position controller for the linear translation, backstepping controller to generate the control laws and the estimator force to estimate the perturbations.

The block diagram of the backstepping controller with an estimator applied for the dynamic part of the model is shown in 


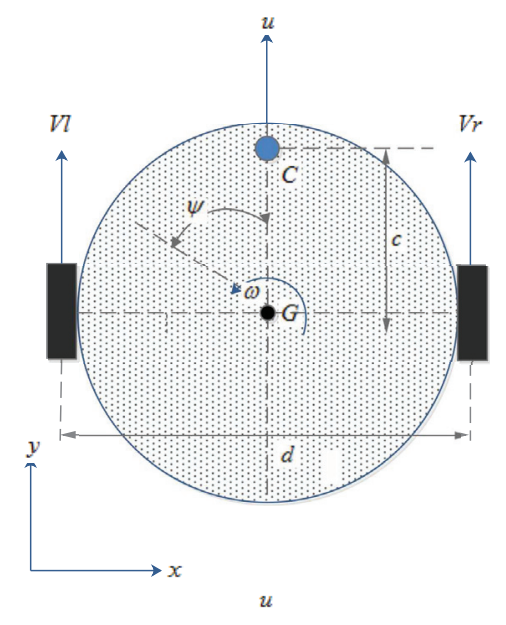

Fig. 1. Model of Wheeled Mobile Robot.

Figure 2.

The kinematic controller used in this work is proposed and

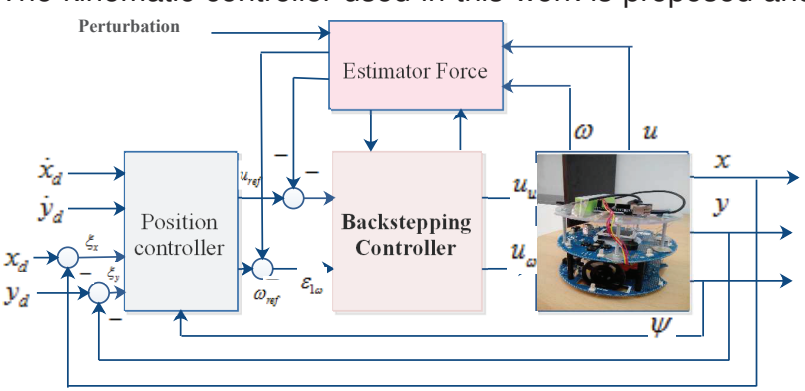

Fig. 2. Backstepping controller with an estimator developed in [10] as:

$$
\left(\begin{array}{c}
u_{r e f}^{p} \\
\omega_{r e f}^{p}
\end{array}\right)=\left(\begin{array}{cc}
\cos \psi & \sin \psi \\
\frac{-\sin \psi}{a} & \frac{\cos \psi}{a}
\end{array}\right)\left(\begin{array}{c}
\dot{x}_{d}+\varepsilon_{x} \\
\dot{y}_{d}+\varepsilon_{y}
\end{array}\right)
$$

Where $\varepsilon_{x}=x_{d}-x$ and $\varepsilon_{y}=y_{d}-y$ the current are position errors, $h(x, y)$ and $h_{d}\left(x_{d}, y_{d}\right)$ are the current and the desired coordinates.

The development and stability analysis of the kinematic controller is detailed in [9].

\section{Backstepping with estimator}

The design of the proposed controller is combines a backstepping controller and the force estimator approach in the presence of disturbances, the dynamic equation of the system (3) can be written as:

$$
\left\{\begin{array}{c}
\dot{u}=\frac{\alpha_{3}}{\alpha_{1}} \omega^{2}-\frac{\alpha_{4}}{\alpha_{1}} u+\frac{u_{r e f}}{\alpha_{1}} \\
\dot{\omega}=\frac{\alpha_{5}}{\alpha_{2}} u \omega-\frac{\alpha_{6}}{\alpha_{2}} \omega+\frac{\omega_{r e f}}{\alpha_{2}}
\end{array}\right.
$$

At the first step, the dynamic error is given in [10] as :

$$
\begin{aligned}
& \varepsilon_{1 u}=u_{r e f}-u \Rightarrow \dot{\varepsilon}_{1 u}=\dot{u}_{r e f}-\dot{u} \\
& \varepsilon_{1 \omega}=\omega_{r e f}-\omega \Rightarrow \dot{\varepsilon}_{1 \omega}=\dot{\omega}_{r e f}-\dot{\omega}
\end{aligned}
$$

And the Lyapunov function can be selected as

$$
V\left(\varepsilon_{1 u}\right)=\frac{1}{2} \varepsilon_{1 u}^{2}, V\left(\varepsilon_{1 \omega}\right)=\frac{1}{2} \varepsilon_{1 \omega}^{2}
$$

Now, Its derivative

$$
\dot{V}\left(\varepsilon_{1 u}\right)=\varepsilon_{1 u} \dot{\varepsilon}_{1 u}, \dot{V}\left(\varepsilon_{1 \omega}\right)=\varepsilon_{1 \omega} \dot{\varepsilon}_{1 \omega}
$$

Where, the virtual controls load input can be defined as:

$$
\left\{\begin{array}{c}
u_{u}^{v}=\dot{u}_{\text {ref }}+K_{1 u} \varepsilon_{1 u} \\
u_{\omega}^{v}=\dot{\omega}_{\text {ref }}+K_{1 \omega} \varepsilon_{1 \omega}
\end{array}\right.
$$

At the next step, the new errors given by:

$$
\left\{\begin{array}{l}
\varepsilon_{2 u}=\dot{u}_{r e f}-\dot{u}+K_{1 u} \varepsilon_{1 u} \\
\varepsilon_{2 \omega}=\dot{\omega}_{r e f}-\dot{\omega}+K_{1 \omega} \varepsilon_{1 \omega}
\end{array}\right.
$$

To reject load disturbance, the related terms of $\tilde{f}$ is added in the Lyapunov candidate functions as follows:

$$
\left\{\begin{array}{l}
V\left(\varepsilon_{1 u}, \varepsilon_{2 u}\right)=\frac{1}{2}\left(\varepsilon_{1 u}^{2}+\varepsilon_{2 u}^{2}+\frac{1}{\beta_{u}} \tilde{f}^{2}\right) \\
V\left(\varepsilon_{1 \omega}, \varepsilon_{2 \omega}\right)=\frac{1}{2}\left(\varepsilon_{1 \omega}^{2}+\varepsilon_{2 \omega}^{2}+\frac{1}{\beta_{\omega}} \tilde{f}^{2}\right)
\end{array}\right.
$$

The addition of this new term of $\tilde{f}$ can be eliminated the dynamic error of the added force $f$.

Where $K_{1 u}, K_{1 \omega}, \beta_{u}$ and $\beta_{\omega}$ are positifs design parameters. and $\tilde{f}$ is the error between $f$ and $f$

$$
\tilde{f}=f-f
$$

The time derivative of the Lyapunov candidate functions (9) can be written as

$$
\left\{\begin{array}{l}
\dot{V}\left(\varepsilon_{1 u}, \varepsilon_{2 u}\right)=\left(\varepsilon_{1 u} \dot{\varepsilon}_{1 u}+\varepsilon_{2 u} \dot{\varepsilon}_{2 u}+\frac{1}{\beta_{u}} \tilde{f} \dot{\tilde{f}}\right) \\
\dot{V}\left(\varepsilon_{1 \omega}, \varepsilon_{2 \omega}\right)=\left(\varepsilon_{1 \omega} \dot{\varepsilon}_{1 \omega}+\varepsilon_{2 \omega} \dot{\varepsilon}_{2 \omega}+\frac{1}{\beta_{\omega}} \tilde{f} \tilde{\tilde{f}}\right)
\end{array}\right.
$$

Or

$$
\dot{V}\left(\varepsilon_{1 u}, \varepsilon_{2 u}\right)=\left[\begin{array}{c}
\varepsilon_{1 u}\left(-K_{1 u} \varepsilon_{1 u}-\varepsilon_{2 u}\right)+ \\
\varepsilon_{2 u}\left({ }^{\prime} r e f-{ }^{*}-K_{1 u} \dot{\varepsilon}_{1 u}\right)+ \\
\frac{1}{\beta_{u}} \tilde{f} \dot{\tilde{f}}
\end{array}\right]
$$

And

$$
\dot{V}\left(\varepsilon_{1 \omega}, \varepsilon_{2 \omega}\right)=\left[\begin{array}{c}
\varepsilon_{1 \omega}\left(-K_{1 \omega} \varepsilon_{1 \omega}-\varepsilon_{2 \omega}\right)+ \\
\varepsilon_{2 \omega}\left(\ddot{\omega}_{r e f}-\ddot{\omega}-K_{1 \omega} \dot{\varepsilon}_{1 \omega}\right)+ \\
\frac{1}{\beta_{\omega}} \tilde{f} \dot{\tilde{f}}
\end{array}\right]
$$

According to the theorem of Lyapunov, we introduce

$$
\dot{\varepsilon}_{2 u}=\left[\begin{array}{c}
\dot{u}_{r e f}-\varepsilon_{1 u}\left(K_{1 u}^{2}+1\right)+ \\
+2 \alpha_{3} \omega \dot{\omega}-\alpha_{4} \dot{u} \\
-\frac{f}{m}+\frac{1}{\beta_{u}} \tilde{f}\left(\dot{f}-\frac{\beta_{u}}{m}\right) \varepsilon_{2 u}
\end{array}\right]
$$

And

$$
\dot{\varepsilon}_{2 \omega}=\left[\begin{array}{c}
\dot{\omega}_{r e f}-\varepsilon_{1 \omega}\left(K_{1 \omega}^{2}+1\right)+ \\
-\alpha_{5}(\dot{u} \omega+u \dot{\omega})-\alpha_{6} \dot{\omega} \\
-\frac{f}{m}+\frac{1}{\beta_{\omega}} \tilde{f}\left(\dot{f}-\frac{\beta_{\omega}}{m}\right) \varepsilon_{2 \omega}
\end{array}\right]
$$

The estimation value can be obtained by solving the following

$$
\dot{f}=\frac{\beta}{m} \varepsilon_{2 u}
$$

Finally, the control inputs of the linear and angular velocities a can be designed as

$$
\begin{aligned}
& u_{u}=\left[\begin{array}{c}
\alpha_{1}\left({ }^{*}{ }_{r e f}+\left(K_{1 u}+K_{2 u}\right) \varepsilon_{2 u}\right. \\
\left.+\left(1-K_{1 u}^{2}\right) \varepsilon_{1 u}\right)-\frac{f_{u}}{m} \\
+2 \alpha_{3} \omega \dot{\omega}-\alpha_{4} \dot{u}
\end{array}\right] \\
& u_{\omega}=\left[\begin{array}{c}
\alpha_{2}\left(\ddot{\omega}_{r e f}+\left(K_{1 \omega}+K_{2 \omega}\right) \varepsilon_{2 \omega}\right. \\
\left.+\left(1-K_{1 \omega}^{2}\right) \varepsilon_{1 \omega}\right)-\frac{f_{\omega}}{m} \\
-\alpha_{5}(\dot{u} \omega+u \dot{\omega})-\alpha_{6} \dot{\omega}
\end{array}\right]
\end{aligned}
$$




\section{Results and Discussions}

In this section, Arduino wheeled mobile robot was used to validate the developed control and to show the performance of the proposed approach.

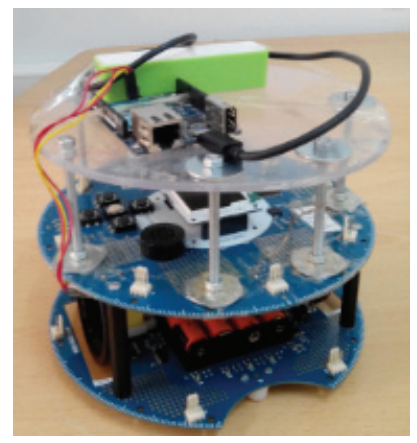

Fig. 3. Arduino robot mobile.

\section{Mechatronics architecture}

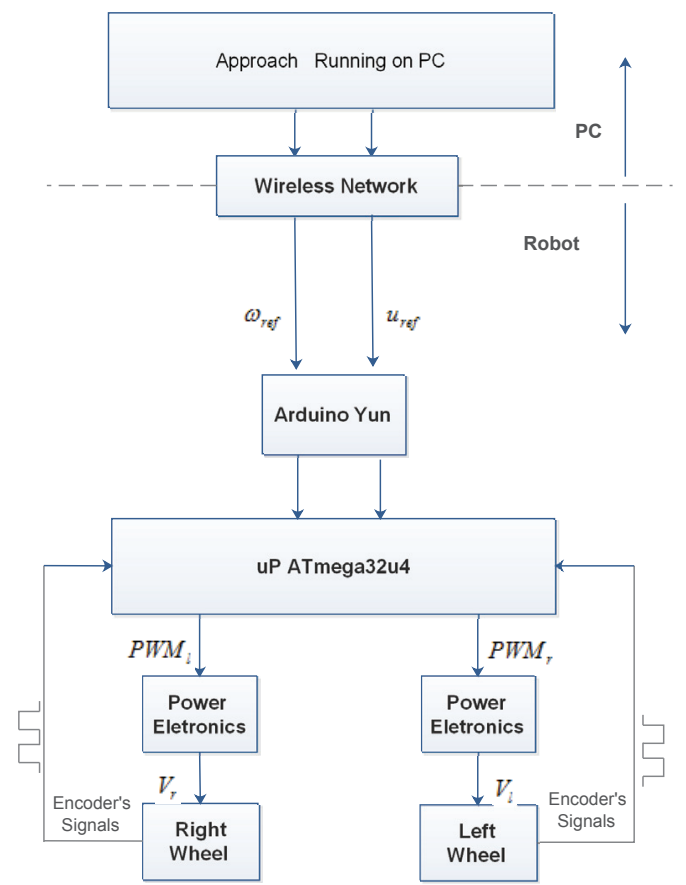

Fig. 4. Mechatronics architecture of the mobile robot

The mechatronics architecture of the control system (see Figure 4) consists of: a) Arduino robot mobile with processors ATmega32u4, its was equipped by two wheels witch are driven by motors having rated torque $20 \mathrm{mN}$ m at $3000 \mathrm{rpm}$ and equipped with incremental encoder counting $\mathrm{Nc}=600$ pulses/turn for the information of point $h$, see Figure 4 ; b) Arduino Yun mounted on the robot to communicate the PC with the robot through a using Wireless network; c) a computer with high-performance processors cards.

\section{Experimental research}

To implement the control structure, we used Matlab/Simulink ${ }^{\circledR}$, the experiences were performed with initial configuration $(2.0,3.0)$, the desired trajectory is circle trajectory, the following parameters are taken as: $K_{1 u}=120, K_{2 u}=75, K_{1 \omega}=14, K_{2 \omega}=2, m=1.50 \mathrm{~kg}$, $\rho=1.225$. The posture robot was provided by encoders. To demonstrate the effectiveness of the proposed approach, at the Time $T=50 \mathrm{sec}$, a external disturbance is add to the system, several tests was applied to the Arduino mobile robot.

The plan $(x, y)$ of the trajectory is represented in the figure Fig. 5 by simulation, the robot track the circle, which was confirmed the good reference tracking. the distance error is show in the figure Fig. 5, its can see the effect of the external perturbation a the time $T=50 \mathrm{sec}$. The error converge towards to zero value as see in figure Fig. 6 The

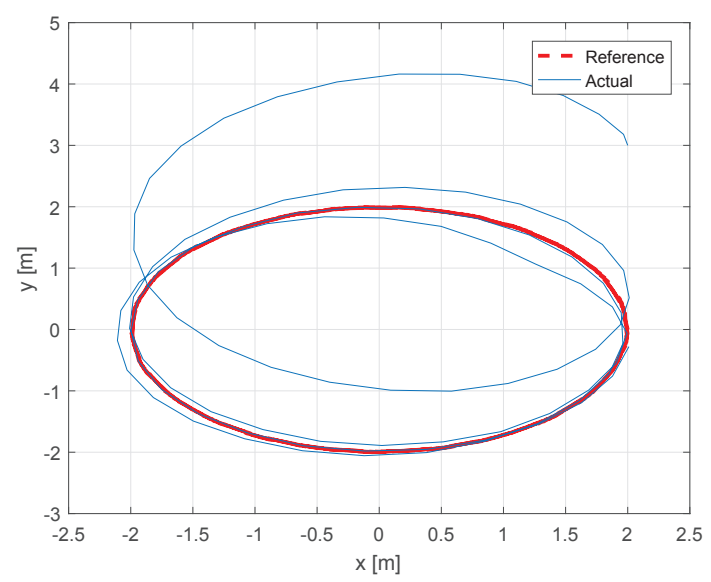

Fig. 5. Robot trajectory.

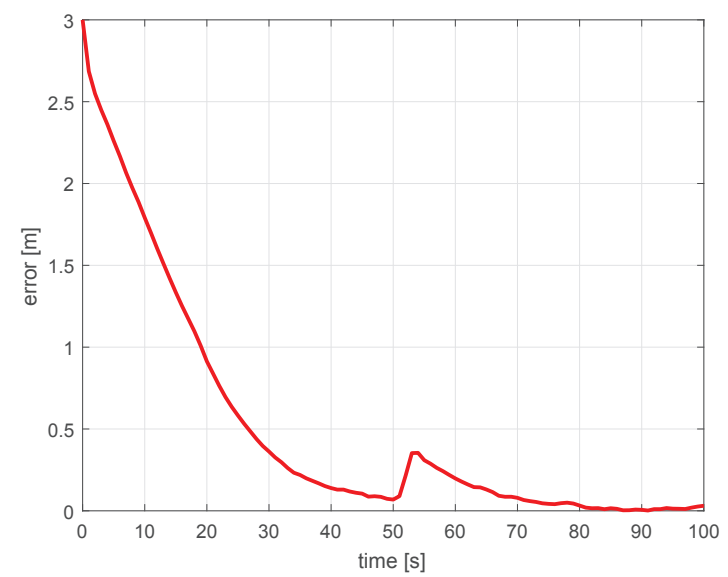

Fig. 6. Distance error.

results obtained by simulation in the figure Fig. 7 is show the good performances of the robust control,and we can see the change of the linear and angular velocities in the moment for this change in the trajectory (50 s). The above mentioned results demonstrate that the robust control is accomplished with precision using the designed control system. The outputs of the backstepping controller with estimator force are represented in the figure Fig. 8, the external disturbance is estimated online. Moreover, force estimated $f$ converge to the unknown force $f$, and the error $\tilde{f}$ converge to zero and we can see the effect of the disturbances in the control laws and the power velocities (see Figure Fig. 9).

\section{Conclusion}

In this paper, a backstepping-Force estimator controller was designed and proposed for wheeled mobile robot Arduino, the estimator force part is add to estimate online the external disturbance witch can be applied to the system. Mechatronics architecture is proposed to validate the control 

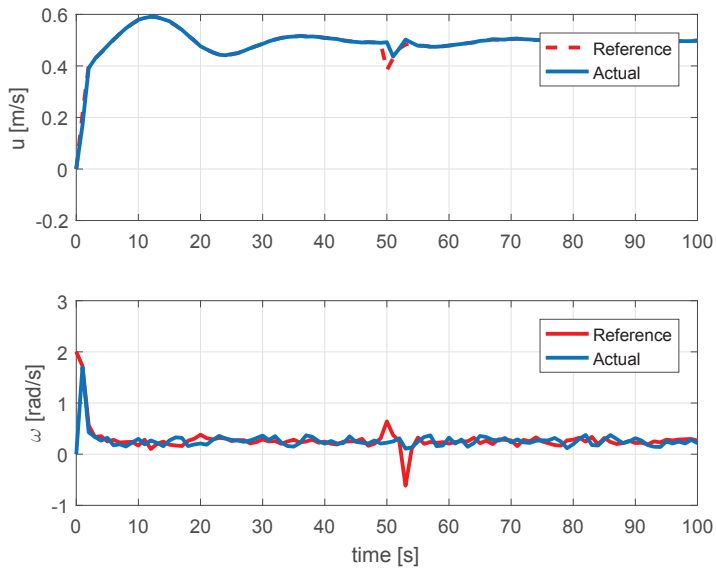

Fig. 7. Linear and angular velocities.

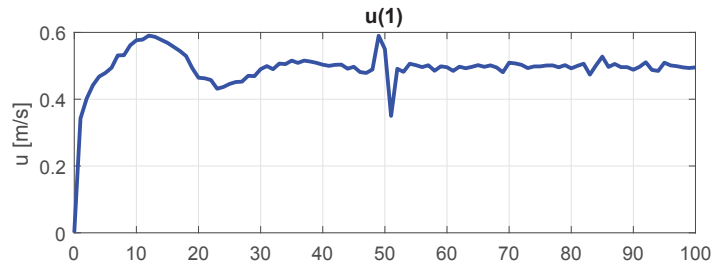

$u(2)$

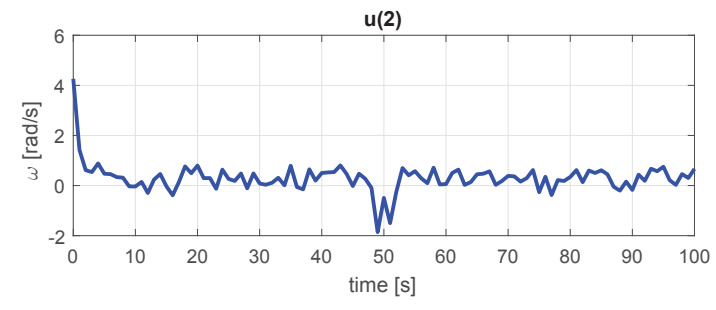

Fig. 8. Control laws.

laws in real implementation. For users, augmented reality interface was developed for planning and execution the trajectories of the robot.

In the near future, we will essentially to tested other approach as sliding mode control (SMC) mode. We can also integrate obstacle avoidance methods with a reference trajectory and the remote control as in [12].

Authors: Dr. Benaoumeur IBARI, Department of Electrical Engineering, University Mustapha Stambouli of Mascara, Algeria,BP 305, route de Mamounia 29000, Mascara, Algeria, Email: ibari_b@yahoo.fr, PhD student Kamel BOUZGOU, Dept. of Electronic, University USTO, BP 1505 El Mnaouar, Oran, Algeria, E-mail: bouzgou_kamel@hotmail.fr. Prof. Zoubir Ahmed-Foitih, Dept. of Electronic, University USTO, BP 1505 El Mnaouar, Oran, Algeria,E-mail: zfoitih@yahoo.fr. Dr. Laredj BENCHIKH, Ibisc Laboratory, University of evry val d'essonne, France, E-mail: Ilaredj@gmail.com.

\section{REFERENCES}

[1] B.Leoncio, B.Paul and S.Miguel.: Wall-climbing robot for inspection in nuclear power plants, Robotics and Automation. In Proceedings.,IEEE International Conference,(1994), 1409_ 1414.

[2] A. Birk and H. Kenn, Roboguard.: a teleoperated mobile security robot, Control Engineering Practice, 10(11), pp. 12591264, 2002.

[3] L. Angel, C. Hernández, C. Diaz-Quintero.: Modeling, simulation and control of a differential steering type mobile robot. In Control Conference (CCC), 32nd Chinese IEEE 2013, 87578762.

[4] T. Mac Thi, C. Copot, R. De Keyser, TD. Tran and V. Thich.: MIMO fuzzy control for autonomous mobile robot, In 3rd Inter-
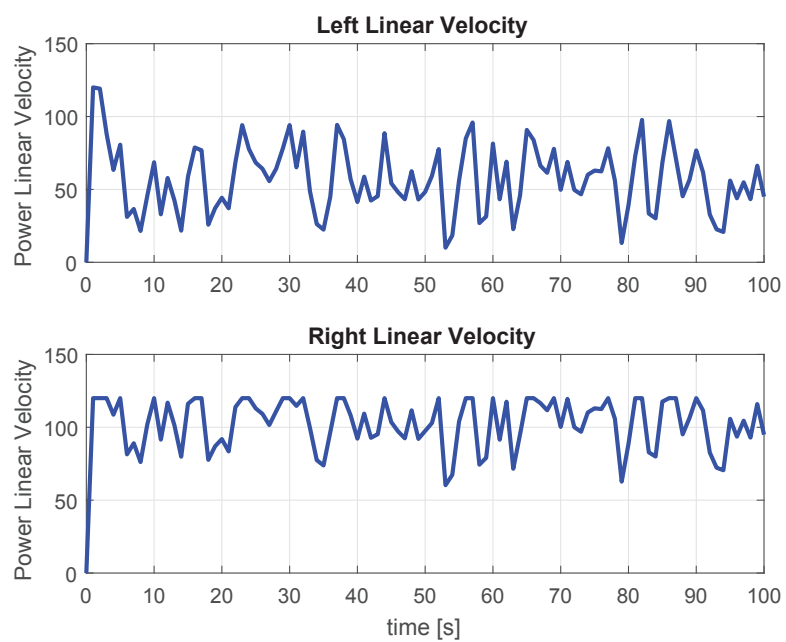

Fig. 9. Power Linear Velocity.

national Conference on Intelligent and Automation Systems, (ICIAS), 2015, pp. 277-282.

[5] AK. Khalaji, SAA. Moosavi.: Dynamic modeling and tracking control of a car with $\mathrm{n}$ trailers, Multibody System Dynamics, 37(2), pp. 211-225, 2016.

[6] FN. Martins, M. Sarcinelli-Filho, R. Carelli.: A Velocity-Based Dynamic Model and Its Properties for Differential Drive Mobile Robots, J. of Intelligent \& Robotic Systems, 85(3),pp. 277292, 2017.

[7] FN. Martins, WC. Celeste, R. Carelli, M. Sarcinelli-Filho, TF. Bastos-Filho.: An adaptive dynamic controller for autonomous mobile robot trajectory tracking, Control Engineering Practice ,16(11), , pp. 1354-1363, 2017.

[8] Z. Shen, Y. Ma and Y. Song.: Robust Adaptive Fault-tolerant Control of Mobile Robots with Varying Center of Mass, IEEE Transactions on Industrial Electronics, 65(3),pp. 2419-2428, 2018.

[9] I. Benaoumeur, B. Laredj, H. E. A. Reda, and A.F, Zoubir.: Backstepping approach for autonomous mobile robot trajectory tracking, Indonesian Journal of Electrical Engineering and Computer Science,2(3), pp. 478-485, 2016.

[10] K.Bouzgou, B. Ibari, L. Benchikh, Z. Ahmed-Foitih, Integral Backstepping Approach for Mobile Robot Control, TELKOMNIKA (Telecommunication Computing Electronics and Control), 15(3), pp. 1173-1180, 2017.

[11] C. De La Cruz and R. Carelli.: Dynamic modeling and centralized formation control of mobile robots, In IEEE Industrial Electronics, IECON 2006-32nd Annual Conference on IEEE, (2006), November, 3880-3885.

[12] Benaoumeur, Ibari, Ahmed-foitih Zoubir, and Hanifi Elhachimi.: Remote Control of Mobile Robot using the Virtual Reality Journal of Electrical \& Computer Engineering, 5(5), 2015. 